\title{
End the culture of fear in healthcare
}

\author{
Navjoyt Ladher \\ clinical editor, The BMJ
}

A key finding of the independent report into deaths at Gosport War Memorial Hospital, where around 600 people received fatal and medically unjustified doses of opioids, was a hospital culture of uncritical deference to doctors and a fear of raising concerns. In an essay this week Philip Darbyshire and David Thompson issue an urgent call for the report to serve as a tipping point in ending professional hierarchies in clinical practice (doi:10.1136/bmj.k4270). Subservience and deference, endemic in health systems, are harming patients, they say, with professionals fearing retribution, disapproval, career limiting consequences, and worse if they dare to question or challenge colleagues.

How do we begin to dismantle the deeply embedded hierarchies of status and profession? Darbyshire and Thompson find answers in the existing evidence base for strong leadership to create safe, open, questioning healthcare organisations, where patients and families are included in decisions, and bad behaviour is not tolerated, no matter the rank. "We do not need more research," they argue, "we need more leaders with the courage and creativity to implement what we already know."
Courageous and creative leadership is essential to tackle issues discussed elsewhere in The BMJ, be that taking action on climate change (doi:10.1136/bmj.k4410), providing healthcare to forced migrants (doi:10.1136/bmj.k4200), having honest conversations about what intensive care can achieve (doi:10.1136/bmj.k4135), or dealing with the drivers of chronic diseases, such as diabetes. On this last point, a feature this week looks at the emerging specialty of lifestyle medicine (doi:10.1136/bmj.k4442). Practitioners use behavioural approaches to encourage change in diet, physical activity, sleep, stress management, and substance use. It offers a promising and sustainable approach to treating and preventing disease and is increasingly becoming part of the medical student's curriculum. Critics say, however, that it needs to prove it can truly make a difference to patients' lives, particularly in the context of wider social determinants of health.

The importance of preventive approaches in health is reflected in the inclusion of "prevention and lifestyle" as one of six new categories in The BMJ Awards next year (doi:10.1136/bmj. $\mathrm{k} 4434$ ). The awards, now in their 11th year, celebrate excellence in UK healthcare. Do enter, or nominate a colleague, if you have a project worthy of recognition (thebmjawards.bmj.com). 